\title{
Library Service Evaluation and Model Research Based on AHP- fuzzy Comprehensive Evaluation Method
}

\author{
Yan-Ran CHEN ${ }^{\mathrm{a},{ }^{*},}$, Ya-Ru LI \\ Library of university of science and technology Beijing,100083 \\ achenyanran00@163.com \\ *Yan-Ran CHEN
}

\begin{abstract}
Keywords: Library, Reader satisfaction, Index system, Analytic hierarchy process (AHP), Fuzzy
\end{abstract} comprehensive evaluation.

\begin{abstract}
Impact on library user satisfaction survey factors practice with different types of library construction weaknesses were made. The readers satisfaction evaluation index system with 20 secondary indicators were established based on collections of resources, facilities, service levels and premises environment, building containing four-level indicators. Using expert questionnaire and AHP (AHP method) to determine the weight of each sub-index, the sub-index data collected by the reader survey, the fuzzy comprehensive evaluation quantitative analysis of integrated library reader satisfaction. Evaluation index system and comprehensive evaluation model based on the comprehensive evaluation of the level of reader satisfaction were established. In order to improve the standard of library construction, optimization recommendations were put forward based on the case study of three different types of libraries.
\end{abstract}

\section{Introduction}

At present, the evaluation method of library reader satisfaction is mainly through the way of questionnaire survey to understand the weak links of library management, and there is no clear and effective general quantitative comparison method. In this research, based on investigation of the library, the multi-level fuzzy comprehensive evaluation method is applied to evaluate the comprehensive servicing ability of library from the perspective of qualitative and quantitative analysis.

This paper takes the reader satisfaction as the direct expression of the evaluation of the service quality of the library. Through the practice investigation of different types of libraries, and the key factors that affect the reader satisfaction degree of the library were analyzed, the comprehensive evaluation index system of Library Readers' satisfaction is constructed. In this study, expert questionnaire survey, analytic hierarchy process (AHP) and fuzzy comprehensive evaluation method to quantify index system, quantitatively analysis of reader satisfaction of different types of library were applied. And finally library readers' satisfaction level were defined.

\section{The Construction of the Index System for the Evaluation of Reader Satisfaction Degree}

The library as a service place, the reader satisfaction degree is not only reflected in the number of the library resources, and other related hardware facilities, service levels and other factors, such as electronic reading facilities, broadband network services, the health, and the premises of business hours signs etc. In this study, the construction of the library reader satisfaction index system is mainly through the investigation practice and analysis of different types of library. The weak points of its satisfaction degree was cleared and based on the current national standards and related documents, it ensured the necessity, operability and testability of evaluation indicators in library reader satisfaction survey. From the library reader satisfaction degree itself, the degree concluded to library resources, hardware facilities, service level, environment 4 first grade indexes, on the basis of which further set up of 20 second grade indexes. The above content has formed the evaluation index system of Library Readers' satisfaction, which is shown in Table 1 . The construction process 
of the index system takes the collection resources as an example. Through the practice investigation of several types of libraries, the weak link of the collection resources is clearly defined.

Table 1. Evaluation index system of Library Readers' satisfaction

\begin{tabular}{|c|c|c|c|}
\hline Index & First index(4) & $\begin{array}{l}\text { Second index } \\
\text { (20) }\end{array}$ & $\begin{array}{c}\text { Weight of second } \\
\text { index } w\end{array}$ \\
\hline \multirow{20}{*}{$\begin{array}{c}\text { Reader } \\
\text { Satisfaction } \\
\text { degree } \\
\text { U }\end{array}$} & \multirow{5}{*}{$\begin{array}{c}\text { Collection } \\
\text { Resource } \\
\text { U1 } \\
(w=0.3194)\end{array}$} & Book ResourcesU11 & 0.3871 \\
\hline & & Periodical Resources U12 & 0.2306 \\
\hline & & Literature Resources U13 & 0.1041 \\
\hline & & Latest Literature RenewalU14 & 0.1799 \\
\hline & & Interlibrary LoanU15 & 0.0983 \\
\hline & \multirow{4}{*}{$\begin{array}{c}\text { Hardware } \\
\text { facilities } \\
\text { U2 } \\
(w=0.2037)\end{array}$} & Seating SatisfactionU21 & 0.5093 \\
\hline & & Necessary Graphic FacilitiesU22 & 0.1634 \\
\hline & & Electronic Reading FacilitiesU23 & 0.2370 \\
\hline & & Indication SignsU24 & 0.0903 \\
\hline & \multirow{8}{*}{$\begin{array}{c}\text { Service level } \\
\text { U3 } \\
(w=0.2670)\end{array}$} & Reception AttitudeU31 & 0.3291 \\
\hline & & Business Service LevelU32 & 0.1049 \\
\hline & & Service TimeU33 & 0.1328 \\
\hline & & Accuracy of Information RetrievalU34 & 0.1013 \\
\hline & & Network Broadband ServiceU35 & 0.2074 \\
\hline & & Literature Retrieval TrainingU36 & 0.0051 \\
\hline & & New Book RecommendationU37 & 0.0087 \\
\hline & & Feedback from ReaderU38 & 0.1107 \\
\hline & \multirow{3}{*}{$\begin{array}{c}\text { Environment } \\
\text { U4 } \\
(w=0.2099)\end{array}$} & HealthU41 & 0.3927 \\
\hline & & Ventilation and HeatingU42 & 0.3108 \\
\hline & & OrderU43 & 0.2965 \\
\hline
\end{tabular}

\section{Weight Analysis of Reader Satisfaction Evaluation Index}

For the established index evaluation system, the weight of each index is determined by the analytic hierarchy process (AHP) and the expert questionnaire, e.g. the judgment matrix is constructed according to the relative importance of all levels of factors, and the weight coefficient of relative importance of each factor is determined by sorting operation. The specific steps are as following: establish hierarchical mechanism model, establish judgment matrix, hierarchical single sorting and consistency check, hierarchy total sorting, and consistency check of hierarchy total ranking. At present, the 1 9 scale method of Saaty is used to score the structure of judgment matrix. But the 1 to 9 scale method, which span is too large, the evaluation between "important" and "relatively important" and other similar language evaluation cannot be chosen. In addition, the evaluation index system of reader satisfaction degree is a typical index to reflect the satisfaction of readers. For the "extremely unimportant" and "very unimportant" indicators have not been selected in the system. Therefore, this research reduces the span of the scale language, constructs judgment matrix by using the 1 5 scale method. The 1 5 scale fuzzy evaluation language are shown in Table 2.

Table 2. The evaluation language of analytic hierarchy process(AHP)

\begin{tabular}{|c|c|}
\hline Scaling & Meanings \\
\hline 1 & Compared to the two factors, it is of the same importance \\
\hline 3 & $\begin{array}{l}\text { Compared to the two factors, the former is a little more important than the } \\
\text { latter. }\end{array}$ \\
\hline 5 & $\begin{array}{l}\text { Compared to the two factors, the former is significantly more important than } \\
\text { the latter. }\end{array}$ \\
\hline 2,4 & Representing the intermediate values of the above adjacent judgments \\
\hline Reciprocal & $\begin{array}{l}\text { The ratio of the importance of factor } I \text { to factor } j \text { is aij, } \\
\text { So the ratio of factor } j \text { to factor } I \text { is aji }=1 / \text { aij }\end{array}$ \\
\hline
\end{tabular}

The most commonly methods for finding its maximum eigenvalues and their corresponding 
eigenvectors are the product method and the square root method. The ratio of the random consistency of the judgment matrix is shown as follows:

$$
C R=C I / R I
$$

$\mathrm{RI}$ is an average random consistency index. The value is given by a large number of random sample statistics experiments, which value is shown in Table 3. When the random consistency ratio CR is less than 0.10 , it is considered that the hierarchical single ranking matrix has satisfactory consistency. Otherwise, the judgment scale value of the judgment matrix element should be adjusted, until the consistency test is satisfied.

Table 3. RI value of average random consistency index

\begin{tabular}{|l|l|l|l|l|l|l|l|}
\hline Scale & $\mathbf{2}$ & $\mathbf{3}$ & $\mathbf{4}$ & $\mathbf{5}$ & $\mathbf{6}$ & $\mathbf{7}$ & $\mathbf{8}$ \\
\hline$R I$ & 0 & 0.52 & 0.89 & 1.12 & 1.26 & 1.36 & 1.41 \\
\hline Scale & $\mathbf{9}$ & $\mathbf{1 0}$ & $\mathbf{1 1}$ & $\mathbf{1 2}$ & $\mathbf{1 3}$ & $\mathbf{1 4}$ & $\mathbf{1 5}$ \\
\hline$R I$ & 1.46 & 1.49 & 1.52 & 1.54 & 1.56 & 1.58 & 1.59 \\
\hline
\end{tabular}

The ranking weights of all index elements to the highest level of the same level are calculated from the highest level to the lowest level by layer by layer. For example, the weights of elements in a certain level are A1, A2,... Am, the ratio of random consistency to the total ranking of the next level is as following:

$$
C R=\sum_{j=1}^{n} a_{j} C I_{j} / \sum_{j=1}^{n} a_{j} R I_{j}
$$

The meaning of every variable is the same as that of a single sorting. When the ratio of random consistency is less than 0.10 , it is considered that the hierarchical single ranking matrix has satisfactory consistency. Otherwise, it is necessary to adjust the evaluation scale of CR.

The judgment matrix is constructed and calculated according to the importance of each factor. Limited to the length, only list the five second index judgment matrix of the subordinates of the first index of "collection resources", which is shown in Table 5. The calculation of other indexes is similar, and the overall ranking of them is tested with $\mathrm{CR}=0.0039<0.10$, which has satisfactory consistency, which shows that the establishment of judgment matrix is ideal.

\section{The Establishment of a Comprehensive Evaluation Model for Reader Satisfaction Degree and an Example analysis of the Comprehensive Evaluation Model of Readers' Satisfaction}

The weighted sum method is the most convenient method in the multi factor fuzzy comprehensive evaluation method. The comprehensive evaluation model of disaster prevention community by weighted average method has good operability, which principle is to get the sum of the product of the weight of evaluation index system and quantized value of the vulnerability index, which is simple, clear and intuitive, so it is also often used by people. The library comprehensive evaluation index model established in this research is as follows:

$$
U=\sum_{j=1}^{m} W(j) \cdot X(i, j)
$$

$\mathrm{U}$ is the comprehensive evaluation index of library reader satisfaction; $\mathrm{W}(\mathrm{J})$ is the weight value of the evaluation index; X (I, J) refers to the quantitative value of the second index. Aiming at each index of the second index system, according to the established evaluation index above and corresponding evaluation values given by questionnaire survey, gradually calculate the high hierarchy indicators, and finally get the comprehensive evaluation score of each library.

This paper selects two university libraries A, B in Haidian District, Beijing and a community library $\mathrm{C}$ as research objects. $\mathrm{A}$ is a library of metallurgical engineering colleges, $\mathrm{B}$ is a comprehensive well-known university library, $\mathrm{C}$ is a Haidian community library. 
The library A was founded in 1950s, the area is about $19000 \mathrm{~m}^{2}$, with 2000 reading seats, 2 million books collection, about twenty thousand students in university. The library B was built in 1998, has an area about $27000 \mathrm{~m}^{2}$, providing 2000 seats, 3 million books collection, and about thirty thousand students in university. The library $\mathrm{C}$ is the community library, building area about $280 \mathrm{~m}^{2}$, more than 20 thousand books, mainly serving for more than 2400 community households residents. Based on field questionnaire survey data, the score of the second index is calculated according to the method described above.

According to the scores of the 20 second evaluation indicators, three different types of library second index radar charts were protracted, and the degree of saturation of shadow zone as shown on the radar of the Fig.1, it could be directly seen that the library readers' satisfaction level, and also the need to be strengthened is also shown in the Fig.1.From the saturation degree of the shadow area in the radar map, it could be directly seen that the comprehensive satisfaction degree of the library and what aspects need to be strengthened. From contrast charts it can be seen that due to the library A is in Colleges of engineering properties, and its age, though after four major building renovations, the collection of resources and facilities, environment have a certain gap with library B. Since its service objects are relatively small, the service quality is higher than library A. B library is a comprehensive university's new library, of which resources, facilities and environment index is relatively prominent. But due to many of their clients, the service level is relatively poor than library A. The radar chart of library $\mathrm{C}$ saturation degree is the worst. Hardware facilities, library resources and service attitude are relatively poor, but the seat satisfaction, working time indexes are relatively good.

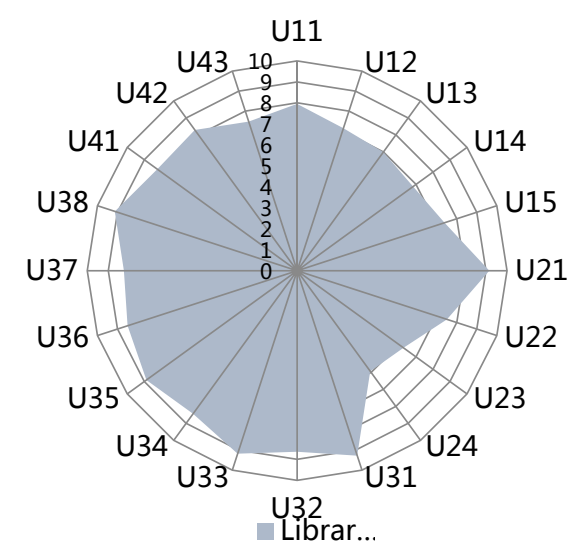

Fig.1 Comparison of level two index of reader satisfaction in A Library

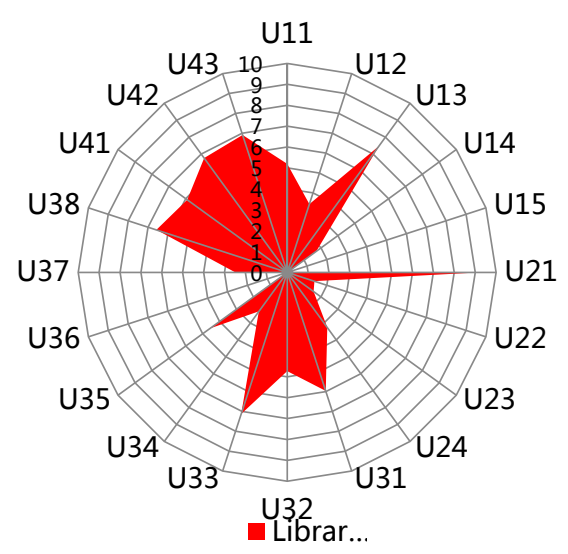

Fig.3 Comparison of level two index of reader satisfaction in C Library

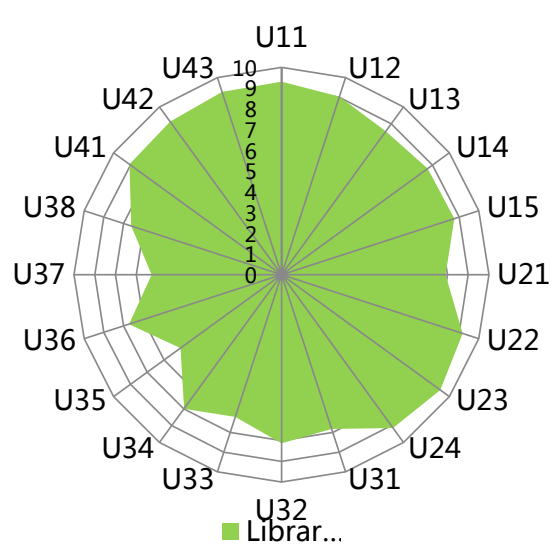

Fig.2B library reader satisfaction comparison

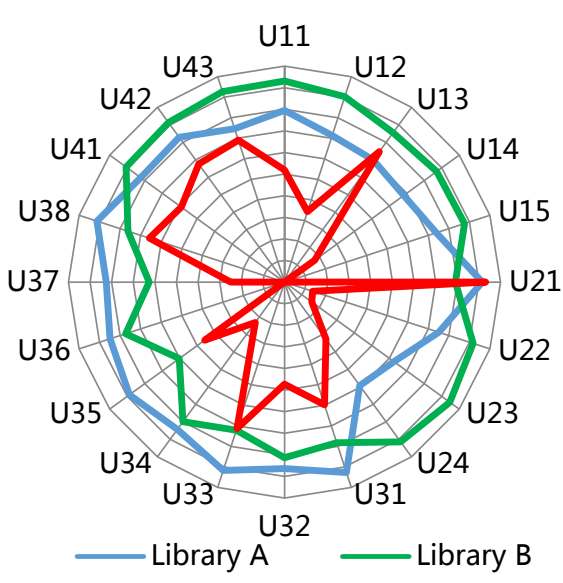

Fig.4 Comparison of grade two index of reader satisfaction in three libraries 
According to the score and weight of the second index, the score of the first index can be calculated, as shown in Table 3. Finally, the scores of the library A were5.02, the library B was 6.40, and library $\mathrm{C}$ was 8.42. Conversion into a 100 percent form for comprehensive evaluation are shown in Table 4:

Table 4

\begin{tabular}{|c|c|c|c|c|}
\hline \multicolumn{2}{|l|}{ Index } & $A$ & B & C \\
\hline \multirow{4}{*}{$\begin{array}{l}\text { First } \\
\text { Index }\end{array}$} & $\begin{array}{l}\text { Collection } \\
\text { resources }\end{array}$ & 7.406742 & 9.004311 & 3.888861 \\
\hline & Hardware facility & 7.746421 & 8.722937 & 4.835539 \\
\hline & Service level & 8.993182 & 7.379241 & 5.339658 \\
\hline & Environment & 8.023308 & 9.144021 & 6.47068 \\
\hline \multicolumn{2}{|c|}{ Total Score } & 8.028931 & 8.542427 & 5.010986 \\
\hline \multirow{2}{*}{\multicolumn{2}{|c|}{\begin{tabular}{|l} 
Score Range \\
Fvaluation Grade
\end{tabular}}} & $7.5-8.5$ & $>8.5$ & $<6.0$ \\
\hline & & Good & Excellent & General \\
\hline
\end{tabular}

From the comprehensive evaluation score, it could be seen that the library B has the highest score in all aspects, followed by the library A and the library C. On this basis, according to different scores the reader satisfaction degree is classified into different grades. They are divided into four grades: excellent, good, general and unqualified. From the evaluation grade, the library B have to improve the level of service for users, the library A needs to strengthen its collection resources, facilities, environment construction. The library $C$ needs to be strengthened in many aspects. Through the implementation of a comprehensive evaluation index system of quantitative analysis on the reader satisfaction in different libraries. It was verified that the index system had good applicability in evaluating the satisfaction level of library readers.

\section{Conclusions}

Through the investigation and practice of the expert questionnaire and analysis of weak links in the present construction of Chinese library reader satisfaction degree, a comprehensive evaluation index system of library reader satisfaction degree were made. By using AHP- fuzzy comprehensive evaluation method quantitative analysis were made and case study were made on 3 different types of library. It is concluded that:

(1) Based on the actual analysis and investigation based on the reader satisfaction of the library, four aspects, 4 first indexes and 20 second indexes were constructed to evaluate the reader satisfaction degree of the library, the library resources, hardware facilities, service level and environment by using the 4 aspects. The evaluation index system has good generality and applicability.

(2) Based on established index system, the AHP- fuzzy comprehensive evaluation method is used to conduct comprehensive quantitative evaluation and analysis of library reader satisfaction degree. The score of the comprehensive reader satisfaction degree is given to the evaluated library, and the application shown that the evaluation method has good maneuverability.

(3) Three typical libraries in Beijing were selected for comprehensive evaluation and analysis. The results showed that the evaluation method is reasonable and effective, and it is easy to identify the weak links of library construction, so as to provide suggestions and support for library construction.

\section{Reference}

[1] chenyanran, Study on the Service Quality Evaluation of the University Library Based on the Theory of Customer Satisfaction-- with An Example of The USTB Library[D].University of science and technology Beijing, 2009.

[2]Xu Yixin, Zhang Min, Wang Yue, Xia Zhiping, Shi Weihua,Practices and Discussion to Improve 
Readers’Satisfaction Rate by University Library[].Library Journal,2013,32(08):59-62

[3] HUANG Houbo, The Research on Changsha city bus passenger satisfaction evaluation by AHP-Fuzzy comprehensive Evaluation[D]. Central South University of Forestry \& Technology.2014

[4] Tao yu-hui. How to Make Fuzzy Consistent Judgement Matrix of the FAHP [J]. Journal of Sichuan Teachers College (Natural Science) 2002,(03):282-285..

[5] code for architectural design of Library JGJ 38-99 